\title{
The Paradox of Value for Money Assessment of PPP Project
}

\author{
Yalan Du \\ School of Management, Tianjin University of Technology, Tianjin 300384, China \\ 1522627362@qq.com
}

\begin{abstract}
In this paper, we analyze the paradox in the application of quantitative evaluation of value for money (VFM) which based on practical case. It is easy to use PPP model to analyze the VFM model, but it is difficult to attract social capital investment when the quasi-operational projects rarely implemented by government. To attract social capital, the government compensation should consider social capital, which may result in government spending in PPP mode is greater than the traditional procurement model of government expenditure, which makes the VFM metric is less than zero, so that the PPP mode project cannot be implemented. For the above paradox, the government should considering the social benefits, and earnestly fulfill the responsibilities of the government, using the method of comprehensive evaluation, and pay attention to qualitative evaluation to decide whether the PPP project is feasible when we proposed application of the PPP model.
\end{abstract}

Keywords: PPP (Publice-Private Partnership); VFM; VFM quantitative analysis; Paradox.

\section{PPP项目物有所值评价悖论}

\author{
堵亚兰 \\ 国家天津理工大学, 天津 中国
}

摘 要: 本文应用实际案例分析我国在物有所值定量评价工作的应用中出现的悖论：准经营性 项目政府实行PPP模式时不进行补贴或者补贴额很少时, 项目识别阶段很容易通过VFM定量分 析, 但是却很难吸引社会资本投资; 为吸引社会资本, 政府进行补偿需要考虑社会资本的基 准收益率, 这就可能造成政府在PPP模式中的支出大于政府传统采购模式的支出, 使得VFM量 值小于零, 使得该项目不能实行PPP模式。针对以上悖论, 提出我国PPP模式应用中, 政府应 综合考虑社会效益, 切实履行政府职责, 采用综合评价的方法, 注重定性评价来决策PPP项目 是否可行。

关键词: PPP; 物有所值; VFM定量分析; 悖论

\section{1. 前言}

中国政府自 2013 年积极倡导用 PPP 模式调动私人资本参与基础设施建设, 财政部要求推广和 运用 PPP 模式时做好项目评估论证, 并在《关于印发政府和社会资本合作模式操作指南（试 行）的通知》（财金 [2014]113 号）中明确要求财政部门会同行业主管部门，从定性和定量 两方面开展物有所值评价工作。对 PPP 项目进行物有所值评价, 能够为政府进行项目采购提 供科学理论依据, 从而提高政府决策水平 ${ }^{1}$ 。由于中国政府对 PPP 项目的大力支持, 各地项目 纷纷进入 PPP 项目识别阶段和准备阶段。这两个阶段物有所值评价必不可少, 大多数项目采 用《政府和社会资本合作物有所值评价指引》（实行）进行物有所值（VFM）评价。但是在实 际操作中, 物有所值定量评价出现不足之处, 本文在物有所值定量评价实际案例的基础上, 对此不足之处加以说明, 并提出解决方案。 


\section{2. 物有所值的内涵及评价方法}

\section{1. 物有所值的内涵}

英国财政部对 VFM 定义 ${ }^{2}$ 是满足用户需求的产品或服务全生命周期成本和质量（或满足期望） 的最优组合。全生命周期指产品或服务的生命周期，VFM 不是选择最低报价的产品或服务。 袁竞峰 ${ }^{3}$ 等学者认为 VFM 评价是用来评论政府组织等机构是否从所购买的产品和服务中获得 了最大收益的一种评价方法，通过它可在经济性（economy）、效率性（efficiency）和效益 性 (effectiveness) 三个方面使资源的利用最大化。Dawn Bidne, Amber Kirby 等在 《The Value for Money Analysis》一书中将 VFM 描述为一个组织运用其可利用资源所能获得的长 期最大利益, 它是国际上普遍采用的一种评价, 旨在实现公共资源配置利用效率最优化。 总之物有所值是用来评价政府、组织等机构是否能够通过项目全生命周期的管理和运营，从 项目的产品或服务中获得最大收益的一种评价方法，对项目的价格以及所有其他形式的成果 进行定性和定量的分析。除价格以外，质量、资源利用、目标实现程度、时效性以及长期运 营效果等因素都要综合评价。通过物有所值评价, 有利于促进资源利用最大化, 更好地实现 基础设施项目建设运营的经济性、效率及效果。

2.2. 物有所值评价方法

目前按照国际上 VFM 评价方法主要包括成本效益分析法、PSC-PPP 对比法，我国财政部指引 中采用 PSC-PPP 对比法。

成本效益分析法

通过比较项目的全部成本和效益来评估项目价值, 用以寻求在投资决策上以最小的成本获得 最大的效益, 常用于评估需要量化社会效益和公共事业项目的价值 ${ }^{4}$ 。在不同的国家或不同领 域，成本效益评价法在收益率的确定、指标选择、评价项目等方面具有一定的差别。PPP 模 式的 VFM 值可以通过公共部门采购模式下的成本与效益减去 PPP 模式下的成本与效益之间的 差值来确定。这种评价方法具有成本和效益识别困难、假设条件理想化的缺点。目前, 应用 成本效益分析法的有澳大利亚、德国等。

PSC-PPP 对比法 (PSC-PPP comparison)

公共部门对照基准 (Public Sector Comparator, PSC) 是在假设建设资金无约束、与 PPP 项 目建设运营期相同、产出标准相同，且考虑不同采购模式交易成本差别的前提条件下，基础 设施项目由传统的公共部门采购模式所需要的全部成本。PSC - PPP 对比法, 就是在基础设 施 PPP 项目立项决策过程中, 将 PPP 模式下基础设施成本 (或者报价) 与 PSC 进行比较, 确定 PPP 模式的 VFM 值, 并最终为立项决策提供量化支持的一种分析评价方法。理论上, VFM $>0$, 说明 PPP 模式比公共部门采购模式更具优势, 应该采用 PPP 模式; VFM $<0$, 说明 PPP 模式与 传统模式相比, 并不具备价值上的优势, 在无资金预算约束的情况下, 该基础设施宜采用传 统的公共部门采购模式。

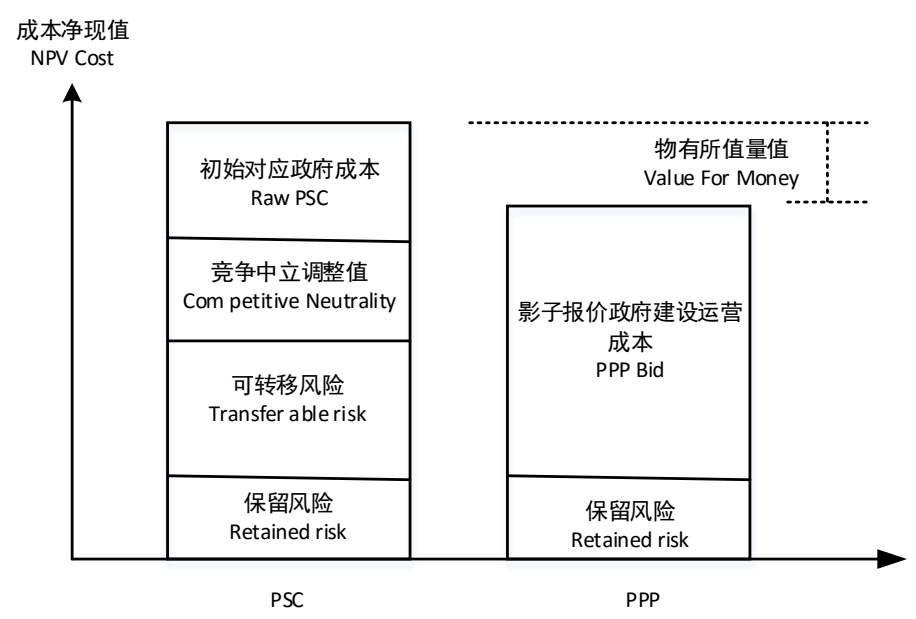

图1 PSC-PPP对比 


\section{3. 物有所值评价在我国的应用}

我国物有所值评价方法主要根据《政府和社会资本合作项目物有所值评价指引》（试行）中 的 PSC-PPP 对比法, 如下图所示。

我国 PSC-PPP 对比法与国际上通用的方法有所差异, 国际上 PPP 值为影子报价或投标报价, 而我国主要是政府建设运营成本和保留风险之和。在项目识别阶段, 如果没有通过物有所值 定量分析, 则不能开展 PPP 项目。准经营性项目实行 PPP 模式时, 政府不出资进行补贴或者 补贴额很少时，进行物有所值定量分析则很容易通过，但是却很难吸引社会资本投资; 为吸 引社会资本, 就需要考虑社会资本的基准收益率后政府进行补偿, 这就可能造成政府在 PPP 模式中的支出大于政府传统采购模式的支出，使得 VFM 量值小于零。

\section{3. 物有所值定量分析案例}

3.1 项目概况

随着 B 镇新型城镇化的稳步推进和工业聚集区快速发展, 现需建设 $20000 \mathrm{~m}^{3} / \mathrm{d}$ 工业污水处理 厂工程，拟采用 PPP 模式建设，该项目该项目占地 21.55 亩，建设总投资为 10380.79 万元， 计划建设期 1 年。项目运作机构图如图 1 所示。

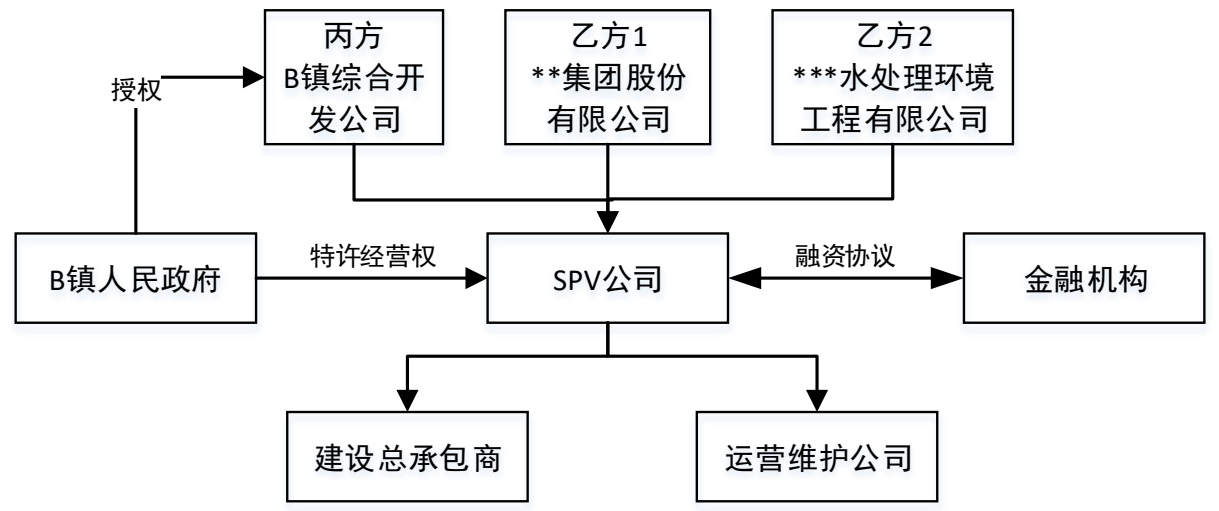

图2 项目运作机构图

3.2 物有所值定量分析

(一) PSC 值计算

(1) 初始 PSC

(1)建设总投资 根据本地原一万吨污水处理厂调研情况，估算该项目建设成本为 10380.79 万 元，建设期 1 年。

(2)运营维护成本

表1 运营维护成本费用表

\begin{tabular}{|c|c|c|c|c|c|c|}
\hline $\begin{array}{l}\text { 计算期 } \\
\text { 项目 }\end{array}$ & 1 & 2 & 3 & 4 & 5 & $6-30$ \\
\hline 外购原辅材料费 & & $1,934.51$ & $2,418.14$ & $2,418.14$ & $2,418.14$ & $2,418.14$ \\
\hline 外购动力费 & & 449.09 & 561.36 & 561.36 & 561.36 & 561.36 \\
\hline 污泥运费 & & 146.00 & 182.50 & 182.50 & 182.50 & 182.50 \\
\hline 工资及福利费 & & 210.00 & 210.00 & 210.00 & 210.00 & 210.00 \\
\hline 修理费 & & 259.37 & 259.37 & 259.37 & 259.37 & 259.37 \\
\hline 其他费用 & & 362.47 & 425.71 & 425.71 & 425.71 & 425.71 \\
\hline 运营维护成本 & & $3,361.44$ & $4,057.08$ & $4,057.08$ & $4,057.08$ & $4,057.08$ \\
\hline
\end{tabular}


(3)第三方收入

表2 第三方收入

\begin{tabular}{ccccccccc}
\hline 计算期 & 1 & 2 & 3 & 4 & 5 & 6 & 7 & $8--30$ \\
\hline $\begin{array}{c}\text { 污水处理量 } \\
\text { (万吨 }\end{array}$ & 584 & 730 & 730 & 730 & 730 & 730 & 730 \\
\hline 单价 (元) & 2.5 & 2.5 & 2.5 & 2.5 & 2.5 & 2.5 & 2.5 \\
\hline 小计 (万元) & 1460 & 1460 & 1460 & 1460 & 1460 & 1460 & 1460 \\
\hline
\end{tabular}

(4)现金流计算值

参照《建设项目经济评价方法与参数》（第三版），案例中折现率采用 $8 \%$ 。经折现计算，得 出初始 PSC 值为 32389.90 万元。

(2) 竞争中立调整

该项目的土地费用为 353.85 万元。国家税务总局《关于污水处理费不征收营业税的批复》（国 税函（2004）1366 号）明确, 污水处理费不征收营业税。所得税方面, 按照 “三免三减半” 政策征收所得税，经折现，该项目的竞争中立调整值为 2149.91 万元。

(3) 风险承担成本

本项目采用比例法确定风险承担成本。财政部门代表、环保部门代表、污水处理厂领导和专 家通过会谈, 确定风险承担成本为 $20 \%$, 可转移风险承担成本占项目全部风险承担成本的 $79 \%$, 剩余为自留风险承担成本。经计算风险承担成本 $6,477.98$ 万元, 可转移风险承担成本

$5,117.60$ 万元, 自留风险承担成本 $1,360.38$ 万元。

(4) 计算PSC值

PSC 值 $=($ 建设成本 - 资本性收益 $)+($ 运营维护成本 - 第三方收入 $)+$ 其他成本 $=41017.79$ 万元

(二) PPPs值计算

在 PPP 模式中, 政府的出资额是 1038. 08 万元, 在建设期初一次性支出。且政府在特许经营 期内不给予财政补贴和收入分成。政府在前期进行的 PPP 项目咨询费 28.45 万元。

PPPs值=影子报价政府建设运营成本+政府自留风险承担成本 $=1038.08+28.45+1360.38=$

2426. 91 (万元)

（三）计算物有所值量值和物有所值指数

物有所值量值 $=$ PSC 值 $-P P P s$ 值 $=41017.79-2426.91=38590.88$

物有所值指数 $=(P S C$ 值 $-P P P s$ 值 $) / P S C$ 值 $\times 100 \%=38590.88 / 41017.79=94.08 \%$

(四) 结论

物有所值量值和物有所值指数为正值, 通过物有所值定量分析。

\section{3 案例分析}

本案例中, 政府只在建设期投资 1038.08 万元, 此后并没有可行性缺口补贴等支出, 所以 VFM 的量值和指数值非常大，很容易通过VFM 定量分析。

该项目的可行性研究报告中, 社会资本方为了正常运营并实现盈利, 将污水处理费定价为 7.2 元/吨。当地政府想要吸引社会资本方投资又不想出资补占, 只能同意社会资本方对污水处理 费的定价, 但是此定价如果没有通过听证会, 则此项目将流产。如果此定价通过听证会, 社 会资本方按照此方案进行污水处理厂的建设运营, 则当地的排污企业被迫承担污水处理厂的 建设运营成本。由此造成当地排污企业污水处理费大幅上升, 利润下降, 从而引发一系列的 社会问题。 


\section{4. 我国物有所值定量分析悖论的解决}

\section{1 政府不能推卸责任}

正如本文开篇提出的悖论: 在一些准经营性 PPP 项目中政府为减少财政支出, 一味不投入或 者少投入，使得在进行 VFM 定量分析时必然通过。然而，由于社会资本的逐利性，必然以抬 高价格来实现收益, 而当价格无法保证时, 不可能吸引社会资本投资。尽管 PPP 热潮出现在 中国财政状况最艰难的时候, 绝大多数的基础设施和公用事业的投资建设将不得不通过 PPP 模式来吸引社会资本实施，但是基础设施和公用事业的建设更多的是获得社会效益而不是经 济效益，所以政府一味地不投入是一种 “甩包袱”思想。

要解决此悖论, 政府应正视自己的职责, 考虑社会资本方的基准收益率和盈利性两个关键因 素，协助社会资本方做好盈亏平衡方案。在保证社会资本方的合理利润的同时，鼓励技术创 新和盈利模式创新, 完善公共服务价格调整机制。

4.2 综合评价, 避免一票否决

在 PPP 项目的实践中, 政府的融资成本往往要低于社会资本的融资成本, 且考虑到社会资本 是一种相对昂贵的资本（基准收益率相对较高），政府就需要对社会资本进行补贴，此时有 可能造成 VFM 小于零，即不通过 VFM 定量分析。此时是否就要一票否决该项目运用 PPP 模式 实施?

由于 VFM 定量分析计算时, 政府付出的代价不仅要考虑财务数据本身, 还要考虑两种体制下 政府提供不同支持条件的财务量化因素、监管成本等。很明显，这些因素的量化是有难度的 ${ }^{5}$, 很难令人信服, 在应用中必然打折扣。而在风险的量化、转移风险的货币化、新增风险的 预测和量化都具有很大的不确定性。如此不确定的数值计算出来的 VFM 量值用于决策出现失 误的可能性就可想而知了。

所以 VFM 定量分析结果小于零时, 应结合定性分析, 综合考虑能否采用 PPP 模式, 必要时应 应用成本效益分析、竞争性招标等方法进行物有所值分析，三种方法集成评价，保证决策的 正确性。

\section{5. 结论}

我国第二批 PPP 示范项目中出现大量的政府付费项目，说明政府已经开始正视自身职责，与 社会资本合作的成熟度正在提高。政府应当充分考虑社会资本方的基准收益率和盈利性两个 关键因素, 积极协助社会资本方做好盈亏平衡方案, 从使用者付费向政府付费转变, 这样就 能有效解决我国物有所值定量分析的悖论，使我国 PPP 项目逐步实现从 “简单模仿” 向 “高 级复杂” 阶段转变, 摒弃之前 “甩包袱” 的错误思想。VFM 定量评价是评价标准的一小部分, VFM 定量分析结果小于零时, 判断 PPP 项目在提高政府效率和社会效益方面的成效, 从定性 方面等因素正确决策是否实施 PPP 项目。

\section{References}

[1]. Hui Sun, Ying Zhou,Zhiqing Fan . The Value for Money Theory of PPP Project Evaluation and Its Application in the International Arena [J]. International Economic Cooperation, 2009, 11:70-74.

[2]. Value for money assessment guidance .Nov 2006.

[3]. Jingfeng Yuan, Fan Wang, Qiming Li. The Research and Application of the Evaluation Method of VFM Infrastructure PPP Project [J]. Modern Management Science, 2012, 01: 27-30.

[4]. Hui Chen,Public-Private-Partnership Gaide[M].Bei Jing: Intellectual Property Press, 2015.

[5]. Yongxiang Jin. The Application Problems of VFM in PPP Project [N]. China Construction News, 2014-06-20006. 